\title{
Giardia AND OTHER PARASITES OF SMALl MAMMALS IN GRAND TETON NATIONAL PARK
}

\author{
WILLIAM D. O'DELL $\bullet$ RAYCHEL A. WATKINS \\ SUZANNE E. MOSHIER $\downarrow$ DEPARTMENT OF BIOLOGY \\ UNIVERSITY OF NEBRASKA $\bullet$ OMAHA
}

\section{AELITA J. PINTER $\bullet$ DEPARTMENT OF BIOLOGICAL SCIENCES UNIVERSITY OF NEW ORLEANS $\bullet$ NEW OLEANS}

\section{$\checkmark \quad$ PROJeCt OBJECTIVES}

The objectives of this study are to document the effects and cost of parasitism on vole populations and to determine the potential of small mammals of Grand Teton National Park to serve as reservoirs of human parasites.

Specific goals for this year were: (1) to continue surveying small mammals for Babesia microti; (2) to collect and identify ticks found with these animals; (3) to determine if $I$. eastoni is a tick vector of $B$. microti; (4) to compare spleen histology of babesiosis in laboratory-infected and uninfected animals; and (5) to continue documentation of the occurrence of Giardia as an intestinal parasite of the montane vole.

\section{$\checkmark \quad$ METHODS}

All animals were trapped at six sites within the boundaries of Grand Teton National Park using Sherman live-traps. After being anesthetized (ketamine), blood was collected by cardiac puncture. Several peripheral blood smears were prepared, fixed in methanol, and stained with Wrights-Geimsa stain. The peripheral blood smears were examined for a minimum of 15 minutes each for the presence of Babesia. If no parasitized cells were found, the specimen was scored as negative. The number of parasitized erythrocytes in a sample of 1000 was determined and recorded as percent parasitemia. Polychromasia was graded on a scale from a trace to 4 plus.

Two capillary tubes were centrifuged in a micro-hematocrit centrifuge for five minutes and the hematocrit determined from a reader. White blood counts were done using a Becton-Dickson Unopette microcollection system for WBC determinations, and a Neubauer hemacytometer for the counts. Reticulocyte counts were done using a Becton-Dickson Unopette Test 5821. Serum was collected from the remaining capillary tubes after centrifugation and stored frozen for future use.

The spleen and liver were removed, weighed and measured. Impression smears of the spleen were fixed in methanol and stained as with the the peripheral blood smears. The remaining portions of liver and spleen were stored in $10 \%$ buffered formalin until preparation for histological examination. Intestinal contents were observed for Giardia. 
Ticks were collected from live-trapped animals. In addition, attempts were made to collect ticks from the grass and soil surrounding the nests using a Berlese funnel as well as a flannel drag. The ticks were maintained on a plaster of Paris medium until needed for the transmission studies. Transmission studies are in progress.

To document the early stages of pathology during babesiosis, laboratory-reared voles were infected by intraperitoneal (IP) injection of $0.1 \mathrm{~mL}$ of infected blood. The infected animals were monitored and treated as described for the trapped animals. Uninfected control animals were included for comparison of normal histology and hematology.

\section{$\checkmark \quad$ RESULTS}

Results of surveys for Babesia microti in Microtus montanus trapped in Grand Teton National Park in the spring and summer, 1987 through 1990 are given in Table 1. Of 257 Microtus montanus, 103 were infected with $B$. microti. Parasitemias ranged from $<0.1 \%$ to $10.0 \%$. In addition, 5 of 12 M. pennsylvanicus and 1 of 3 Arvicola richardsoni were parasitized by $B$. microti. None of 40 Peromyscus maniculatus was infected.

Reticulocyte numbers were significantly greater (Student's t-test; $P<0.001$ ) in infected animals. The results of the reticulocyte counts of infected and uninfected $M$. montanus are summarized in Figure 1. Only $7.7 \%$ of the uninfected animals had reticulocyte levels $>10 \%$, while $69 \%$ of the infected animals had reticulocyte counts $>10 \%$. Polychromasia in peripheral blood smears of infected animals was always $2+$ or greater, and was consistent with the elevated reticulocyte counts.

The spleens of all infected animals were significantly enlarged (Student's t-test; $\mathbf{P}<0.001$ ). The spleens of $77 \%$ of uninfected animals measured $<20 \mathrm{~mm}$ in length while $98 \%$ of the spleens of infected animals measured $>20 \mathrm{~mm}$ in length with $73 \%$ of these spleens measuring $>30 \mathrm{~mm}$. The mean spleen size of nine laboratory-reared $M$. montanus was $14.9 \pm 1.8 \mathrm{~mm}$ long by $4.4 \pm 0.5 \mathrm{~mm}$ wide. The mean spleen size of infected wild animals $(32.0 \pm 6.8 \times 11.8 \pm 2.3 \mathrm{~mm})$ was more than twice that of uninfected or laboratory-reared animals. Differences in hematocrit values were unremarkable.

\begin{tabular}{llllll} 
Table 1. & \multicolumn{4}{l}{$\begin{array}{l}\text { Incidence (infected animals/total examined) of Babesia microti in Microtus montanus from six sites } \\
\text { within Grand Teton National Park, Wyoming. NC collection. }\end{array}$} \\
\hline SITE & 1987 & 1988 & 1989 & 1990 & TOTAL \\
\hline 1 & NC & $3 / 4$ & NC & NC & $3 / 4$ \\
2 & NC & $9 / 10$ & $2 / 4$ & NC & $11 / 14$ \\
3 & $3 / 13$ & $6 / 27$ & $8 / 10$ & $20 / 50$ & $37 / 100$ \\
4 & $6 / 14$ & $6 / 11$ & $4 / 13$ & $16 / 35$ & $32 / 73$ \\
5 & $2 / 3$ & $1 / 1$ & $15 / 42$ & NC & $18 / 46$ \\
6 & NC & $4 / 20$ & NC & NC & $4 / 20$
\end{tabular}




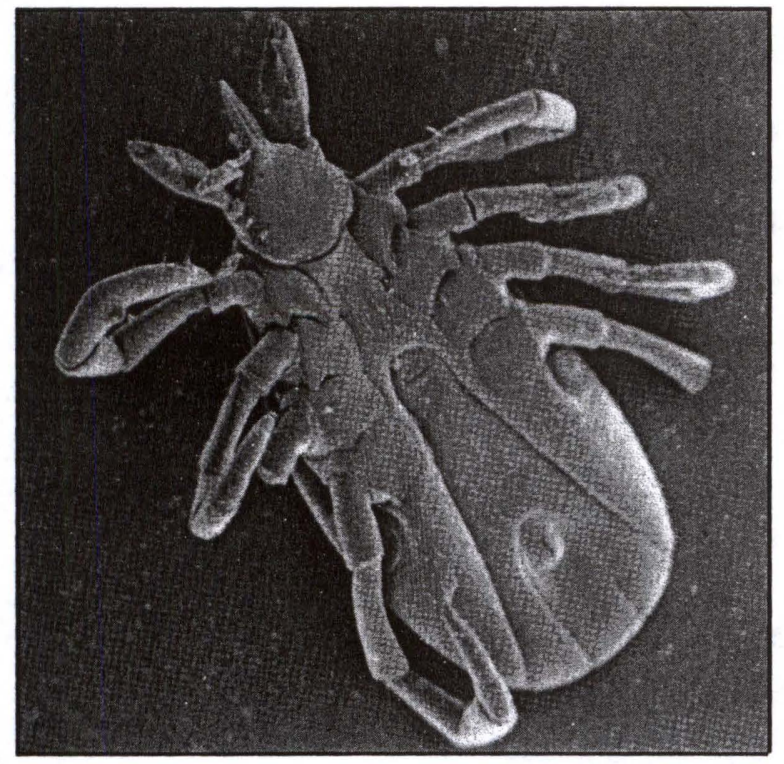

Scanning electron micrograph of ventral view of Lxodes eastoni, a newly discoverd tick in Grand Teton National Park.

Infections of Hepatozoon sp. were concurrent with $B$. microti in $13 \mathrm{M}$. montanus and in $3 \mathrm{M}$. pennsylvanicus. Eight $M$. montanus were infected with Trypanosoma sp., while the bacterium, Grahamella sp., was found in the erythrocytes of nine other $M$. montanus Four adult female ticks were removed from trapped voles this season. This brings the total to twenty-three ticks, 17 adult females and 6 nymphs, which have been removed from $M$. montanus. The only species we haveidentified is Lxodes eastoni. The females from this season laid eggs which hatched to produce larvae. These larvae are being used in the transmission study. Attempts to capture ticks from around the nest were unsuccessful. Analyses of the field studies for 1991 and of the pathology studies on laboratory-infected voles are not completed.

\section{$-\quad$ CONCLUSIONS}

The montane vole and the meadow vole are the primary reservoirs of Babesia microti in Grand Teton National Park. Splenomegaly and reticulocytosis are important diagnostic signs of babesiosis in montane voles. Hematocrit is not a reliable diagnostic tool. The voles are also the hosts for a number of other

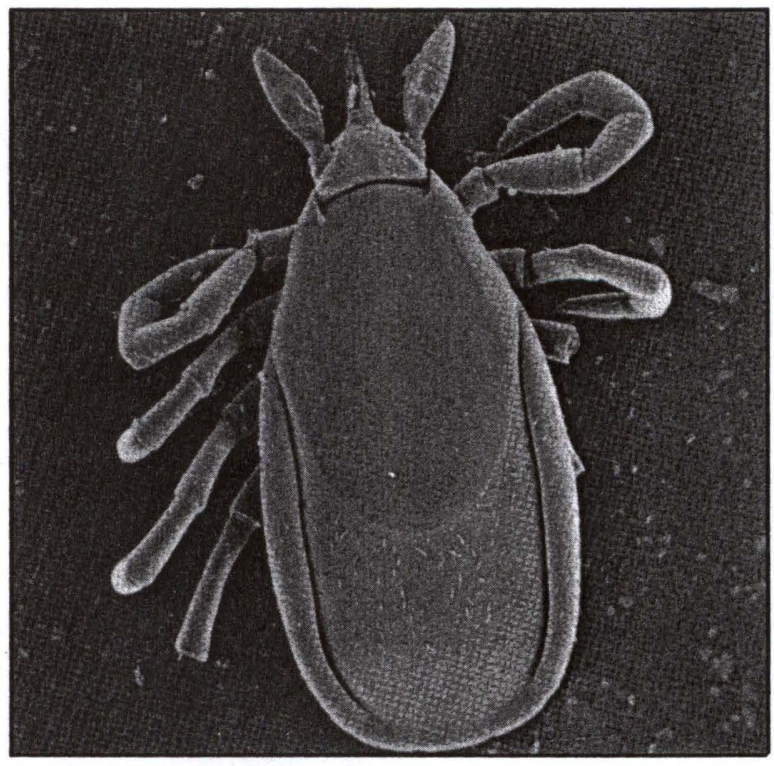

Scanning electron micrograph of dorsal view of Lxodes eastoni.

parasites, any or all of which must certainly impact on their health and survival. The white-footed mouse appears not to be a significant reservoir for $B$. microti in this ecosystem. Ixodes eastoni is the most likely candidate for the vector of Babesia. Transmission studies will be necessary to document this tick as a vector.

\section{$-\quad$ LITERATURE CiTed}

Pinter, A. J., W. D. O'Dell, and R. A. Watkins. 1988. Intestinal parasites of small mammals from Grand Teton National Park. J. Parasitol. 74(1):187-188.

Watkins, R. A., W. D. O'Dell, and A. J. Pinter. 1989. Redescription of flagellar arrangement in the duck intestinal flagellate, Cochlosoma anatis and description of a new species, Cochlosoma soricis n. sp. from shrews. J. Protozool. 36:555-559.

Watkins, R. A., S. E. Moshier, W. D. O'Dell, and A. J.Pinter. Splenomegaly and reticulocytosis caused by Babesia microti infections in natural populations of the montane vole, Microtus montanus. J. Protozool. (in press). 